American Journal of Applied Sciences 8 (5): 447-451, 2011

ISSN 1546-9239

(C) 2010 Science Publications

\title{
Screening of Lactic Acid Bacteria for Antifungal Activity against Aspergillus oryzae
}

\author{
Belal Jamal Muhialdin and Zaiton Hassan \\ Department of Science and Technology, University Sains Islam Malaysia \\ Bandar Baru Nilai, 71800 Nilai Negeri Sembilan, Malaysia
}

\begin{abstract}
Problem statement: The growth of spoilage fungi have been a global concern because of the economy loses and the health hazard of the mycotoxins produced by the spoilage fungi. Approach: A total of 137 lactic acid bacteria isolated from Malaysian fruits and fermented foods were screened for antifungal activity using dual agar overlay method and well method against $A$. oryzae. Results: 23 isolates showed inhibition activity after $72 \mathrm{~h}$ incubation at $30^{\circ} \mathrm{C}$. Supernatant of three isolates with strong antifungal activity was evaluated by well method and they inhibited the growth of the fungi at $30^{\circ} \mathrm{C}$ for $72 \mathrm{~h}$. LAB supernatant reduced the mass growth of Aspergillus oryzae when incubated for 7 days at $30^{\circ} \mathrm{C}$. The isolates were identified using API $50 \mathrm{CH}$ as Lactobacillus brevis G004, Lactobacillus fermentum Te007 and Pediococcus pentosaceus Te010. Conclusion: The three isolates studied inhibited the growth of the mycelia and conidia germination of the fungi which indicate the possibility of using $\mathrm{LAB}$ isolates as biopreservative.
\end{abstract}

Key words: A. oryzae, antifungal activity, API 50CHL, Lactic Acid Bacteria (LAB), global concern, antifungal activity, isolates inhibited, spoilage moulds

\section{INTRODUCTION}

Many chemical preservatives that target fungi growth in food have been approved and used for many years. Recently the consumers are looking and demanding for products without chemical preservatives and still maintain good shelf life and safe. Biopreservation refers to extended shelf life and enhanced safety of foods by growth of the natural or added microflora and their antimicrobial products (Ross et al., 2002). Growth of spoilage moulds on food and fruits result major economic losses and may be causing serious health hazard (Pitt and Hocking, 2009; Hernandez-Castillo et al., 2010).

Several microorganisms such as Lactic Acid Bacteria (LAB) produce antimicrobial compounds which can be applied as food preservatives (AL-Haj et al., 2010). LABs are considered Generally Recognized As Safe (GRAS). LABs produce antimicrobial agents including organic acids, hydrogen peroxides and bacteriocin. LAB has been known for many years and play important role in the production of a variety of fermented foods. Health benefits of LAB are known to give positive influence in the gastrointestinal of humans (Cogan et al., 1995; Hafidh et al., 2010). Certain Lactobacillus species were reported to have antifungal activity when evaluated by agar overlay assay against wide range of spoilage fungi. The antifungal activity of L. coryniformis subsp cornyformis was stable when heated at high temperature and at $\mathrm{pH}$ 3-4.5 (Magnusson and Schnurer, 2001).

Most of the antifungal capacity of LAB studied is due to the production of an antifungal protein or proteinaceous compound and some of the LAB like $L$. plantarum and $L$. sanfrancisco produce special organic acids with antifungal properties (Corsetti et al., 1998; Lavermicocca et al., 2003). Currently, the only biopreservative compound that could be added to food is the one produced by lactic acid bacteria (Gardiner et al., 2000; Corcoran et al., 2004). The objective of this study is to evaluate the antifungal activity of LAB isolated from Malaysian fermented food and fruits with the hope that the compound can be applied as biopreservatives.

\section{MATERIALS AND METHODS}

Isolation of lactic acid bacteria: Lactic acid bacteria were isolated from Malaysian fruits and fermented foods. Appropriate dilutions were prepared using sterile peptone water $(0.1 \% \mathrm{w} / \mathrm{v}) .100 \mu \mathrm{L}$ were spread on modified de Man Rogosa and Sharpe agar (MRS) with $\left(\begin{array}{ll}0.8 \% & \mathrm{CaCo}_{3}\end{array}\right)$ and incubated under anaerobic

Corresponding Author: Belal Jamal Muhialdin, Department of Science and Technology, University Sains Islam Malaysia, Bandar Baru Nilai, 71800 Nilai Negeri Sembilan, Malaysia Tel: +6016-3817246 Fax: +606-7987010 
conditions at $30^{\circ} \mathrm{C}$ for 48 h (De Man et al., 1960; Wanchai et al., 2007). Colonies showing clear zones around them streaked on MRS agar to obtain pure colonies. The isolates were stored at $4^{\circ} \mathrm{C}$ or at $-20^{\circ} \mathrm{C}$ for long term with $20 \%$ glycerol.

Fungi preparation: The fungi Aspergillus oryzae was obtained from the Microbiology Laboratory, Faculty of Food Science, University Putra Malaysia. The target fungi were chosen to represent potential spoilage fungi especially in bakery products. Fungi were grown on Potato Dextrose agar (PDA, Oxoid) plates at $25^{\circ} \mathrm{C}$ for 5 days and stored at $4^{\circ} \mathrm{C}$.

Initial screening for antifungal activity against targeted fungi: Inhibition activity of the isolates was determined by the overlay method as described by Magnusson and Schnurer (2001). LAB was inoculated in two $2 \mathrm{~cm}$ lines on MRS agar plates and incubated at $30^{\circ} \mathrm{C}$ for $24 \mathrm{~h}$ and incubate anaerobically. The plates were then overlaid with $10 \mathrm{ml}$ of malt extract soft agar (0.05\% malt extract and $1 \%$ agar Oxoid) containing $10^{5}$ conidia/ml of $A$. oryzae. After $48 \mathrm{~h}$ of aerobic incubation at $30^{\circ} \mathrm{C}$, the zone of inhibition was measured. The scale used was: - no visible inhibition, + no fungal growth on $0.1-3 \%$ of plate area/bacterial streak, ++ no fungal growth on $3-8 \%$ of plate area/ bacterial streak, +++ no fungal growth on more than $8 \%$ of plate area/bacterial streak. Inhibition tests were done in duplicate.

Cell free supernatant preparation: The isolates were inoculated into MRS broth and incubated for $24 \mathrm{~h}$ at $30^{\circ} \mathrm{C}$. The cell free supernatant was prepared by centrifuging the broth $(11500 \times \mathrm{g}$ for $10 \mathrm{~min})$. The bacteria were grown to $\mathrm{OD}_{540}=2.6$, then the supernatant of each isolates was filtrated using sterile filtered (0.45 $\mu \mathrm{m}$-pore-size filter, Millipore).

Determination of inhibitory activity on spore germination by well method: The highest activity of the isolates which showed strong activity was further tested using the well method as described by Magnusson and Schnurer (2001). Fungi $10^{5}$ conidia/ml was mixed with MRS agar and allowed to solidify. Then, wells of size $5 \mathrm{~mm}$ were made using cork borer and $20 \mu \mathrm{L}$ MRS agar was pipetted to cover the base of the well to avoid leaking of the supernatant. $60 \mu \mathrm{L}$ were added to each well and the plates were incubated at $30^{\circ} \mathrm{C}$ for 24,48 and $72 \mathrm{~h}$. Mycelia growth inhibition zone was measured by diameter.

Determination of inhibitory activity on mycelia growth by well method: The isolates that showed strong activity against spore germination were tested to determine if they have the inhibition activity against mycelia growth. The supernatants were prepared as described above. Small portion of five day-old mycelia of $A$. oryzae were placed in the middle of a Potato Dextrose Agar (PDA) plate. Wells were made in MRS agar and $60 \mathrm{~mL}$ of the supernatant were placed in the wells to test their inhibition activity against the mycelia growth. The plates were incubated for $30^{\circ} \mathrm{C}$ for 24,48 and $72 \mathrm{~h}$. The inhibition activity was determined by the size of the mycelia measured from the middle of fungi colony.

Fungal biomass inhibition: $10 \mathrm{~mL}$ of supernatant from $\mathrm{LAB}$ isolate were placed in $50 \mathrm{~mL}$ flask and inoculated in triplicate with MRS broth containing $10^{5}$ conidia/ml of A. oryzae. The cultures were incubated at $30^{\circ} \mathrm{C}$ for 7 days. Fungal growth was collected on Whatman \# 1 filter paper (Whatman International, Maidstone, England) and dried in oven at $50^{\circ} \mathrm{C}$ for 2 days. The average fungal biomass was calculated for each test fungus and compared with the fungal biomass of positive controls which is fungi grown in MRS broth.

API 50 CH kit identification of isolates: Three isolates (G004, Te007 and Te010) that showed strong fungal growth inhibition activity in all the tests were identified using API $50 \mathrm{CH}$ kit (API system, BioMérieux, France). Strips were incubated at $30^{\circ} \mathrm{C}$ as recommended by the manufacturer. Changes in colors either to yellow, blue or green were observed after 24 and $48 \mathrm{~h}$. The results were analyzed with API WEB (BioMerieux).

\section{RESULTS}

Isolation of lactic acid bacteria: A total of 137 isolates that showed clear zone on the modified agar with $(0.8 \%$ $\mathrm{CaCO}_{3}$ ) against tested microorganisms were collected from different Malaysian fruits and fermented foods. These isolates were tested for the potential of antifungal activity against $A$. oryzae using overlay method. Results showed that approximately 18\% (23/137) of the isolates had good activity, 27\% (37/137) had low activity and $56 \%$ (77/137) had no activity. The isolates with strong activity were selected for this study

Inhibition activity of the isolates in the overlay method: Out of the 137 isolates, 23 isolates showed good inhibitory activity against conidia germination of the fungi in the overlay method (Fig. 1). (Table 1) consisting of twelve isolates from fermented guava juice, four from tempeh, three from tempoyak, two from fermented apple and two from fermented banana juice. The activities of the isolates were varied in strong and moderated activities. 
Am. J. Applied Sci., 8 (5): 447-451, 2011

Table 1: Lactic acid bacteria isolates from different fermented food and fruits showing inhibitory activity on Aspergillus oryzae conidia germination after $48 \mathrm{~h}$ incubation at $30^{\circ} \mathrm{C}$ by dual agar overlay method ${ }^{\mathrm{a}}$

\begin{tabular}{lll}
\hline LAB Strain & A. oryzae & Source \\
\hline G003 & ++ & fermented guava juice \\
G004* & +++ & fermented guava juice \\
G005 & ++ & fermented guava juice \\
G006 & +++ & fermented guava juice \\
G007 & ++ & fermented guava juice \\
G008 & +++ & fermented guava juice \\
G009 & + & fermented guava juice \\
G012 & ++ & fermented guava juice \\
G014 & + & fermented guava juice \\
G016 & +++ & fermented guava juice \\
G017 & ++ & fermented guava juice \\
G018 & ++ & fermented guava juice \\
Tp003 & + & tempoyak \\
Tp008 & + & tempoyak \\
Tp017 & ++ & tempoyak \\
Te007* & +++ & tempeh \\
Te010* & +++ & tempeh \\
Te016 & ++ & tempeh \\
Te017 & ++ & tempeh \\
Ap012 & + & apple \\
Ap019 & ++ & apple \\
Ba001 & + & banana \\
Ba008 & ++ & banana \\
\hline aShow the & $+c t i n g$ &
\end{tabular}

${ }^{\mathrm{a}}$ : Show the activity of the twenty three isolates in dual agar overlay method: $(+)$ no fungal growth on $0.1-3 \%$ of plate area, $(++)$ no fungal growth on $3-8 \%$ of the plate area, $(+++)$ no fungal growth on $>8 \%$ of the plate area

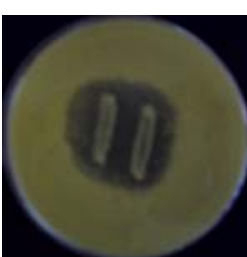

(24)

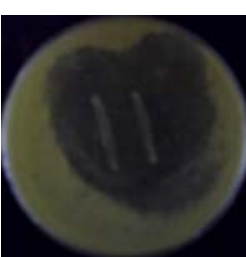

(48)

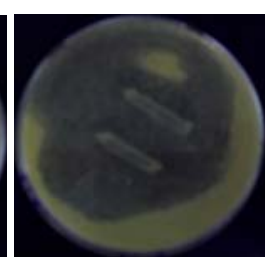

(72)
Fig. 1: Clear zone of growth inhibition of Aspergillus oryzae formed around the streak lines of lactic acid bacteria (Te007) incubated at $30^{\circ} \mathrm{C}$ for 24 , 48 and $72 \mathrm{~h}$ by dual agar overlay method

Inhibition of conidia and mycelia growth in the well method: Three isolates (3/23) had very strong inhibitory against conidia germination and the mycelia growth of A. oryzae when tested by well method. Both mycelia growth and conidia germination were inhibited by all the LAB isolates with different range of activity (Fig. 2 and 3). The most active isolate was G004 followed by Te007 and Te010, LAB isolates maintained the activity for more than 21 days incubated at $30{ }^{\circ} \mathrm{C}$ when treated with the supernatant of the three isolate.

Biomass inhibition of fungi: The growth of tested fungi was inhibited by the isolates Te010 and G004 in the liquid system and inhibition activity from the isolate Te007 was very low compare to the control. The highest inhibition activity was observed from the isolate Te010 followed by G004 and Te007 (Table 2).
Table 2: Biomass inhibition activity of $A$. oryzae by LAB isolates incubated for 7 days at $30^{\circ} \mathrm{C}$

\begin{tabular}{lr}
\hline Isolate & A. oryzae \\
\hline Control & $39.8 \mathrm{mg}$ \\
$\mathrm{G} 004$ & $13.3 \mathrm{mg}$ \\
$\mathrm{Te} 007$ & $14.8 \mathrm{mg}$ \\
$\mathrm{Te} 010$ & $6.1 \mathrm{mg}$ \\
\hline
\end{tabular}

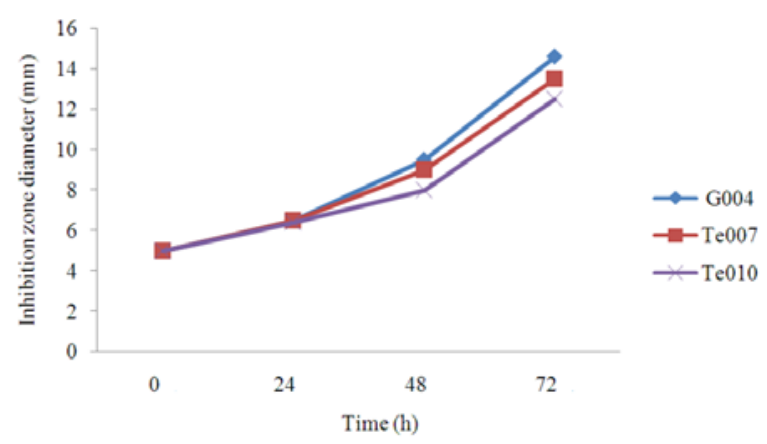

Fig. 2: Inhibition of Aspergillus oryzae conidia germination by LAB supernatant using agarwell-diffusion assay incubated at $30^{\circ} \mathrm{C}$ for $48 \mathrm{~h}$

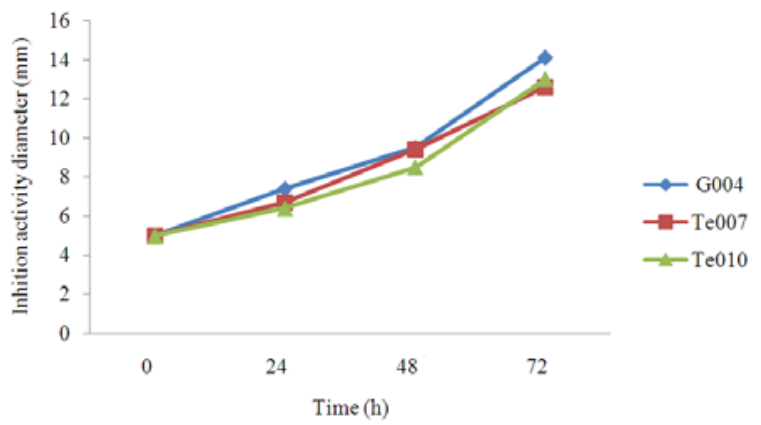

Fig. 3: Inhibition of Aspergillus oryzae mycelia by LAB supernatant using agar-well-diffusion assay incubated at $30^{\circ} \mathrm{C}$ for $48 \mathrm{~h}$

API 50 CH kit identification of the isolates: Results from API 50CH test kits and API web identified the two LAB isolates from tempeh (Te007) as Lactobacillus fermentum 2 and (Te010) as Pediococcus pentosaceus, while the isolate from fermented guava juice (G004) as Lactobacillus brevis.

\section{DISCUSSION}

This preliminary work highlights the antifungal activity of LAB isolated from different fruits and fermented food available in Malaysian market. The isolates (23) showed strong antifungal activity against the fungi A. oryzae. Three of the isolates, Te007 and $\mathrm{Te} 010$ isolated from tempeh, G004 isolated from 449 
fermented guava juice show good inhibition activity against spore germination and mycelia growth. Moreno et al. (2002) reported that LAB isolated from fermented food tempeh produced bacteriocins that inhibited the growth of Gram-positive indicators, including Listeria monocytogenes. More reports from Malaysia show that the isolates ( $L$. casei LA17, L. plantarum LA22 and $L$. paracasei LA02) inhibited the growth of bacteria ( $B$. cereus, Staphylococus aureus, Salmonella enterica, Listeria monocytogenes, Escherichia coli and Lactococcus lactis). LAB was isolated from the fermented fish budu and showed antimicrobial activity (Liasi et al., 2009).

The growth of the mycelia and the conidia were inhibited by the supernatant of the LAB isolates by the well method, the conidia were more affected by the supernatant than the mycelia and the inhibition activity of the supernatant was higher against the conidia. Growth of the mycelia was inhibited and there was no conidia forming observed from the survived mycelia. $L$. rhamnosus was reported to inhibit the growth of many spoilage and toxigenic fungi including species in the genera Aspergillus, Penicillium and Fusarium. (Plockova et al., 2001). Laitila et al. (2002) and Lavermicocca et al. (2003) suggested that the antifungal activity of $L$. plantarum could be the results of many organic acids such as lactic, acetic and phenyllactic acids. However, Strom et al. (2002) found that L. plantarum MiLAB 393 produced three antifungal substances: cyclo (L-Phe-L-Pro), cyclo (LPhe-trans-4-OH-L-Pro) and phenyllactic acid which showed antifungal activity against five fungi. $L$. coryniformis subsp. coryniformis strain $\mathrm{Si3}$ was reported to have broad inhibitory spectrum against molds and yeast (Magnusson and Schnurer, 2001). The mass of the fungi was reduced when the fungi was treated with LAB supernatant. The identification of the isolate by the API 50CHL kit showed that the isolates Te007 and Te010 were Lactobacillus fermentum 2 and Pediococcus pentosaceus, respectively. The isolate G004 was identified as Lactobacillus brevis. Since more than one compound is responsible for the antimicrobial activity, the specific compound or combination of compounds need to be further studied for their potential use as food biopreseravtion.

\section{CONCLUSION}

Lactic acid bacteria isolated from different Malaysian environment inhibited the growth of $A$. oryzae. 23 of the isolates had inhibition activity against A. oryzae and the spectrum range was varied between fair and strong. The activity was observed from the bacteria cells and their supernatant in liquid and solid medium. The isolates identified as Te007 as $L$. fermentum 2, Te010 as Pediococcus pentosaceus and G004 as L. pentosus. We concluded that LAB isolates from Malaysian fermented foods and fruits have inhibition activity against spoilage fungi and it have potential to be use as food preservatives.

\section{ACKNOWLEDGMENT}

This study has been supported by the Faculty of Science and Technology, Universiti Sains Islam Malaysia.

\section{REFERENCES}

AL-Haj, N.A., N.I. Mashan, M.N. Shamsudin, H. Mohamad and C.S. Vairappan et al., 2010. Antibacterial activity of marine source extracts against multidrug resistance organisms. Am. J. Pharmacol. Toxicol., 5: 95-102. DOI: 10.3844/ajptsp.2010.95.102

Cogan, T.M., T.M. Cogan and J.P. Accolas, 1995. Dairy Starter Cultures. 1st Edn., John Wiley and Sons, USA., ISBN-10: 0471185841, pp: 290.

Corcoran, B.M., R.P. Ross, G.F. Fitzgerald and C. Stanton, 2004. Comparative survival of probiotic lactobacilli spray-dried in the presence of prebiotic substances. J. Applied Microbiol., 96: 1024-1039. PMID: 15078519

Corsetti, A., M. Gobetti, J. Rossi and P. Damiani, 1998. Antimould activity of sourdough lactic acid bacteria: Identification of a mixture of organic acids produced by Lactobacillus sanfrancisco CB1. Applied Microbiol. Biotechnol., 50: 253-256. PMID: 9763693

De Man, J.D., M. Rogosa and M.E. Sharpe, 1960. A medium for the cultivation of lactobacilli. J. Applied Bacteriol., 23: 130-135. DOI: 10.1111/j.1365-2672.1960.tb00188.x

Gardiner, G.E., E. OSullivan, J. Kelly, M.A.E. Auty and G.F. Fitzgerald et al., 2000. Comparative survival rates of human-derived probiotic Lactobacillus paracasei and L. salivarius strains during heat treatment and spray drying. Applied Environ. Microbiol., 66: 2605-2612.

Hafidh, R.R., A.S. Abdulamir, L.S. Vern and F.A. Bakar, 2010. The inhibition of human pathogens: Trichophyton rubrum and Trichoderma harzianum by a natural product. Am. J. Biochem. Biotechnol., 6: 40-46. DOI: 10.3844/ajbbsp.2010.40.46 
Hernandez-Castillo, F.D., F. Castillo-Reyes, G. Gallegos-Morales, R. Rodriguez-Herrera and C.N. Aguilar-Gonzalez. 2010. Lippia graveolens and Carya illinoensis organic extracts and there in vitro effect against Rhizoctonia solani Kuhn. Am. J. Agric. Biol. Sci., 5: 380-384. DOI: 10.3844/ajabssp.2010.380.384

Laitila, A., H.L. Alakomi, L. Raaska, T. MattilaSandholm and A. Haikara, 2002. Antifungal activities of two Lactobacillus plantarum strains against Fusarium moulds in vitro and in malting of barley. J. Applied Microbiol., 93: 566-576. PMID: 12234339

Lavermicocca, P., F. Valerio and A. Visconti, 2003. Antifungal activity of phenyllactic acid against molds isolated from bakery products. Applied Environ. Microbiol., 69: 634-640. DOI: 10.1128/AEM.69.1.634-640.2003

Liasi, S.A., T.I. Azmi, M.D. Hassan, M. Shuhaimi and M. Rosfarizan et al., 2009. Antimicrobial activity and antibiotic sensitivity of three isolates of lactic acid bacteria from fermented fish product, Budu. Malaysian J. Microbiol., 5: 33-37.

Magnusson, J. and J. Schnurer, 2001. Lactobacillus coryniformis subsp. coryniformis strain $\mathrm{Si} 3$ produces a broad-spectrum proteinaceous antifungal compound. Applied Environ. Microbiol., 67: 1-5. DOI: 10.1128/AEM.67.1.1-5.2001

Moreno, M.R., J.J. Leisner, L.K. Tee, C. Ley and S. Radu et al., 2002. Microbial analysis of Malaysian tempeh, and characterization of two bacteriocins produced by isolates of Enterococcus faecium. J. Applied Microbiol., 92: 147-157. PMID: 11849339
Pitt, J.I. and A.D. Hocking, 2009. Fungi and Food Spoilage. 3rd Edn., Springer, USA., ISBN-10: 0387922067, pp: 519.

Plockova, M., J. Stilesm, J. Chumchalova and R. Halfarova, 2001. Control of mould growth by Lactobacillus rhamnosus VT1 and Lactobacillus reuteri CCM 3625 on milk agar plates. Czech J. Food Sci., 19: 46-50.

Ross, R.P., S. Morgan and C. Hill, 2002. Preservation and Fermentation: Past, present and future. Int. J. Food Microbiol., 79: 3-16. PMID: 12382680

Strom, K., J. Sjorgen, A. Broberg and J. Schnurer, 2002. Lactobacillus plantarum MiLAB 393 produces the antifungal cyclic dipeptides cyclo(LPhe-L-Pro) and cyclo(L-Phe-trans-4-OH-L-Pro) and 3-phenyllactic acid. Applied Environ. Microbiol., 68: 4322-4327. PMID: 122200282

Wanchai, P., Pramuan, S. and W. Nisakorn, 2007. Identification and evaluation of lactic acid bacteria for Pla-som (fermented fish) starter. Proceedings of the 2nd International Conference on Fermentation Technology for Value Added Agriculture Products, May 23-25, Kosa Hotel, Khon Kean, Thailand, pp: 1-6. 